\title{
Metformina: más allá del control glucémico
}

\author{
Jairo A Morantes-Caballero* \\ Gabriel A Londoño-Zapata* \\ Manuela Rubio-Rivera* \\ Análida Elizabeth Pinilla-Roa**
}

\begin{abstract}
"Médico Residente. Especialidad de Medicina Interna. Departamento de Medicina Interna. Facultad de Medicina. Universidad Nacional de Colombia. Bogotá, Distrito Capital. Colombia

"Profesora Asociada. Doctorado en Educación. Médico Internista. Magíster en Educación con Énfasis en Docencia Universitaria. Formación en Nutrición y Diabetes. Departamento de Medicina Interna. Facultad de Medicina. Universidad Nacional de Colombia. Bogotá, Distrito Capital. Colombia. Correspondencia: Dr. Jairo Morantes. Dirección: Carrera 30 No. 45-03. Facultad de Medicina, Edificio 471. Departamento de Medicina Interna, oficina 510. Universidad Nacional de Colombia, Sede Bogotá. Teléfono: (57) (1)3165000 ext. 15011. Correo electrónico: jamorantesc@unal.edu.co.
\end{abstract}

\section{RESUMEN}

Introducción: la metformina es una biguanida que disminuye gluconeogénesis e incrementa la recaptación de glucosa en los músculos, sin embargo, más allá del glucémico se han documentado beneficios adicionales como la disminución de complicaciones crónicas derivadas de la hiperglucemia, entre ellas las cardiovasculares y del síndrome metabólico per se. Objetivo: identificar los efectos de la metformina diferentes al control control glucémico en población con diabetes mellitus, con el fin de contribuir a difundir el conocimiento. Materiales y método: tres revisores independientes realizaron la búsqueda en distintas bases de datos entre ellas Pubmed y ScienceDirect, utilizando los términos Metfomin AND Cardiovascular disease AND inflamatory response AND Hyperlipidemia, Biguanides, Diabetes Mellitus, Diabetes complications, Obesity, Vascular diseases AND Cancer; y Metfomina y enfermedad cardiovascular, metformina y cáncer se seleccionaron los artículos desde el año 2010, encontrando 13828 artículos, de los cuales se incluyeron 144. Conclusión: más allá del control glucémico, la metformina, modifica la "memoria metabólica", reduce mediadores inflamatorios y el grosor de pared arterial, disminuye factores trombóticos y reduce la prevalencia de falla cardiaca logrando impactar la morbimortalidad y mediante cambios moleculares o genéticos, tiene potencial uso como anticancerígeno. El clínico debe conocer estos efectos para favorecer su pronto inicio en los casos indicados. MÉD.UIS. 2017;30(1):57-71.

Palabras clave: Metformina. Diabetes Mellitus. Proteínas Quinasas Activada por AMP. Obesidad. Enfermedades Vasculares. Neoplasias.

\section{Metformin: beyond the glycemic target}

\section{ABSTRACT}

Introduction: the metformin is a biguanide which main action is to decrease hepatic glucose output, primarily by decreasing gluconeogenesis, and increase glucose uptake by muscles. However, beyond the glycemic target, additional benefits have been documented like a decrease in chronic complications to hyperglycemia, including cardiovascular comorbility and metabolic syndrome. Objetive: to identify effects of metformin other than glycemic control in patients with diabetes mellitus in order to help disseminate knowledge. Materials and methods: three independent reviewers searched in different databases of PubMed and ScienceDirect using the DeCS and MeSH terms: Metfomin AND Cardiovascular disease AND inflamatory response AND Hyperlipidemia, Biguanides, Diabetes Mellitus, Diabetes complications, Obesity, Vascular diseases AND Cancer, selecting the items since 2010 year and prior to warrant mention. Search based publications that were considered most relevant and, additionally, a manual search of the referenced articles in publications retrieved in the initial search was conducted, 13828 articles were found but 144 were included finally. Conclusion: beyond glycemic control, Metformin, modifies the "metabolic memory", reduces inflammatory mediators and thickness of arterial wall, decreases thrombotic factors and reduces the prevalence of heart failure making an impact morbidity and mortality and because of molecular or genetic changes, it has potential use as anticarcinogenic. The physicians should know it to facilitate the early administration of this medication when it is indicated. MÉD.UIS. 2017;30(1):57-71.

Keywords: Metformin. Diabetes Mellitus. AMP-Activated Protein Kinases. Neoplasms. Obesity. Vascular Diseases.

Artículo recibido el 14 de Febrero de 2016 y aceptado para publicación el 4 de Noviembre de 2016 
¿Cómo citar este artículo?: Morantes-Caballero JA, Londoño-Zapata GA, Rubio-Rivera M, PinillaRoa AE. Metformina: más allá del control glucémico. MÉD.UIS. 2017;30(1):57-71.

\section{INTRODUCCIÓN}

Según el reporte de estadística americana de diabetes 2014', durante el año 2012 el 9,3\% de la población americana presentaba diabetes mellitus, generando costos médicos directos de 176 billones de dólares y un número importante de muertes siendo esta la séptima causa de mortalidad para ese año. Las enfermedades cardiovasculares generan aproximadamente una de cada tres muertes entre los pacientes con Diabetes Mellitus tipo $2\left(\mathrm{DM}_{2}\right)^{2}$, por lo que el control de los factores de riesgo cardiovasculares es parte importante dentro del tratamiento en este grupo de pacientes, más allá del control glucémico. Es así como distintas sociedades favorecen el uso de un fármaco antidiabético que, además de intervenir la glucemia, logra impactar sobre las comorbilidades, principalmente la cardiaca, pero, disminuyendo el riesgo de hipoglucemia, la cual conlleva a aumento en morbilidad y mortalidad 3 , es así, como la metformina prescrita en aproximadamente el $80 \%$ de los pacientes con $\mathrm{DM}_{2}^{4}$, es el fármaco con mayor recomendación por la Asociación Americana de Diabetes (ADA) en su guía $2016^{5}$, estimándose que el número de personas a nivel mundial que reciben metformina es de más de 120 millones por año $0^{6}$. Por ello, el objetivo de esta revisión fue identificar los distintos efectos de la metformina adicionales del control glucémico, con el fin de contribuir a difundir el conocimiento sobre este medicamento.

\section{Materiales y Métodos}

Tres revisores independientemente realizaron la búsqueda en distintas base de datos Pubmed y ScienceDirect, utilizando los términos MeSH y DeCS: Metfomin, Metformin AND Cardiovascular disease, Metformin AND inflamatory response, Metformin and Hyperlipidemia, Biguanides, Diabetes Mellitus, AMPActivated Protein Kinases, Diabetes complications, Neoplasms, Obesity, Vascular diseases y Metfomina AND Cancer; y Metfomina y enfermedad cardiovascular, metformina y cáncer, seleccionando los artículos de los últimos cinco años y otros previos relevantes, como revisiones de tema o trabajos originales, la búsqueda se realizó en junio del año 2015. Con base a lo anterior, se seleccionaron las publicaciones que se consideraron más sobresalientes. Adicionalmente, se realizó una búsqueda manual de los artículos referenciados en las publicaciones recuperadas en la búsqueda inicial. Una vez obtenidos los artículos, se organizaron por apartados de interés y se descartaron los resultados duplicados (Ver Figura 1).

\section{Resultados}

La metformina es un antidiabético oral, del grupo de las biguanidas, primera línea de tratamiento de los pacientes con $\mathrm{DM}^{7}$ y casos puntuales de Diabetes Mellitus tipo 1 (DM1) $)^{8}$. Mucho antes que se conocieran claramente los mecanismos de acción a nivel molecular, la metformina se postuló como primera opción de tratamiento por el beneficio al aumentar la sensibilidad a la insulina en los tejidos periféricos y, por la consecuente, disminución en la resistencia a esta, con poco riesgo de hipoglucemia y disminución discreta del peso"; además, por demostrar en ensayos clínicos, la reducción del riesgo de complicaciones macrovasculares que son la mayor causa de morbimortalidad en el paciente con $\mathrm{DM}_{2}{ }^{10}$.

La metformina actúa mediante la disminución de la producción hepática de glucosa por disminución de la gluconeogénesis, sensibilización de los tejidos periféricos a la insulina, efecto antilipolítico por lo cual disminuye la cantidad de ácidos grasos disponibles para la gluconeogénesis ${ }^{11,12}$. Los mecanismos moleculares de estos efectos parecieran ser múltiples y, a nivel celular, la mitocondria ocupa un papel clave ${ }^{13}$.

\section{INHIBICIÓN DE LA GLUCONEOGÉNESIS}

Estudios recientes evidencian que la acción clave para la inhibición de la gluconeogénesis ocurre en la mitocondria. La metformina inhibe la isoforma mitocondrial de la enzima glicerol fosfato deshidrogenasa, enzima que cataliza la conversión de glicerol fosfato a dihidroxiacetona fosfato, esto disminuye la concentración de Nicotin Adenin Dinucleótido (NAD) en el citosol y, por ende, aumenta la relación nicotin adenin dinucleótido reducido $(\mathrm{NADH}) / \mathrm{NAD}$ en este compartimento y de manera secundaria disminuye esta relación en la mitocondria, lo cual a su vez restringe la conversión de lactato a piruvato, evitando así el uso de estos sustratos para la gluconeogénesis ${ }^{14}$. De esta manera, la producción 
hepática de glucosa disminuye y los excesos de glicerol y lactato son liberados al plasma13.

Otro mecanismo de acción propuesto recientemente es la inactivación del complejo I mitocondrial de la cadena de electrones, lo cual disminuye la oxidación del NADH y, por ende, la producción del Adenosin Trifosfato (ATP) mitocondrial y aumenta la disponibilidad de Adenosin Difosfato (ADP) y Adenosin Monofosfato (AMP). Para balancear la poca producción de energía, la célula inhibe procesos que requieran uso de ATP, entre estos la gluconeogénesis; se cree que este proceso es frenado por los altos niveles de AMP, que inhibe la actividad de la fructosa 1,6 bifosfatasa, enzima reguladora de la gluconeogénesis (Ver Figura 1)13,15,16.

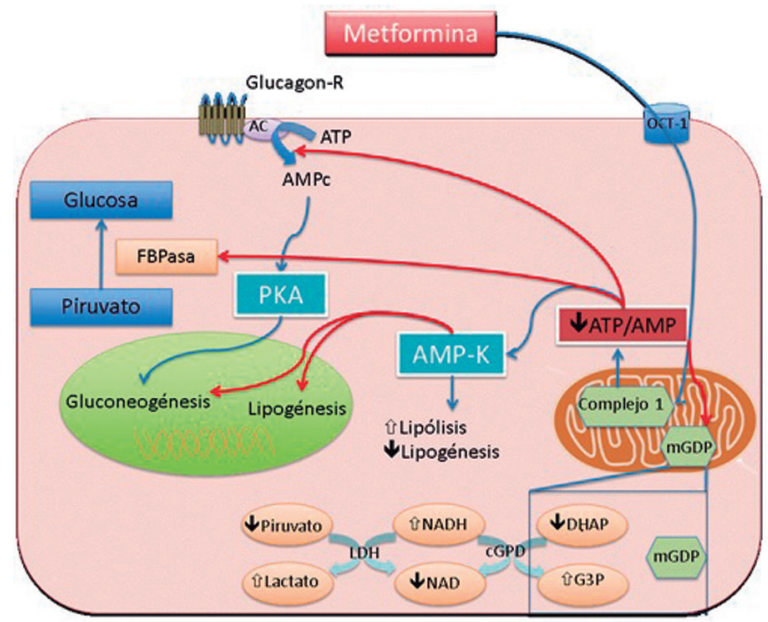

Figura 1:Mecanismo de acción de la metformina

Diagrama esquemático del efecto anti-hiperglicemiante de la metformina en el hepatocito. La metformina es transportada dentro de la célula por el OCT1, resultando en una inhibición de la cadena respiratoria mitocondrial sobre el complejo 1 por mecanismos aún desconocidos. El déficit energético resultante conlleva a una reducción en el consumo energético traducido por disminución de la gluconeogénesis la cual se media por varias vías. Primero la razón ATP/AMP disminuye por aumento del AMP; este déficit de ATP disminuye la glucólisis por ser necesaria durante dicho proceso enzimático. El AMP tiene funciones de señalización intracelular, inhibe alostéricamente la señalización de la Protein cinasa A (PKA) a través de la supresión de la adenilato ciclasa activada por el receptor de glucagón, vía encargada de activar la transcripción nuclear de enzimas de la gluconeogénesis. Alostéricamente inhibe la FBPasa enzima determinante en la vía metabólica de la gluconeogénesis. Activa la AMPK la cual tiene actividad regulatoria principalmente sobre la vía de los lípidos, pero tambien tiene efecto sobre la gluconeogénesis. Otro mecanismo de supresión de la gluconeogénesis mediado por la metformina a nivel mitocondrial, se debe a la supresión de la isoforma de Glicerolfosfato Deshidrogenasa (mGPD), el cual media la conversión del glicerol 3 Fosfato (G3P) a Dihidroxiacetona Fosfato (DHAP). Dicha disminución lleva a una disminución propiamente de la via gluconeogénica, a su vez, por el aumento del NADH secundario al disbalance, produce un aumento del lactato por disminución de su conversión a piruvato mediada por la lactato deshidrogenasa.

Fuente: Tomado y modificado de Ferrannini E. N Engl J Med. 2014;371:1547-8, Rena G, Diabetologia. 2013;56:1898-906.

\section{AUMENTO DE LA SENSIBILIDAD A LA INSULINA}

La metformina se comporta como un sensibilizador de la insulina, a través de varios mecanismos; presenta un efecto positivo en la expresión del receptor de insulina, mediado por la modulación de la fosforilación de la sub-unidad beta de Tirosina Cinasa (LKB1, Liver Kinase B1 o STK11, Serine/Threonine Kinase), secundario a la activación de la Kinasa activada por AMP (AMPK) por mecanismos descritos anteriormente ${ }^{17}$. Además, aumenta los niveles séricos de la incretina, Péptido Similar al Glucagón (GLP1) ${ }^{18}$, proteína producida en las células $L$ intestinales bajo el estímulo de los alimentos, cuya función es estimular la secreción de insulina, pero a su vez, mejorar la sensibilidad de los tejidos periféricos a esta, también produce enlentecimiento del vaciamiento gástrico y supresión de la liberación de glucagón; estudios en animales plantean que el GLP1 también estimula regeneración y aumento de la masa de la célula Beta $^{19}$. El GLP1 se une a su receptor específico en tejidos periféricos y es rápidamente degradado en plasma por la enzima dipeptidilpeptidasa-4, la cual al parecer también disminuye su concentración sérica con la administración de metformina, aumentando así la vida media del GLP1, con efecto final de menor resistencia periférica a la insulina ${ }^{18,20}$.

\section{INDICACIONES DE PRESCRIPCIÓN}

\section{DIABETES MELLITUS TIPO 2}

En ausencia de contraindicaciones, la metformina es considerada el tratamiento de primera línea para la $\mathrm{DM} 2$, dada su costo-efectividad, efecto antihiperglucemiante con bajo riesgo de hipoglucemia, efecto favorable en el peso, con tolerancia generalmente adecuada y efectos adversos poco frecuentes; dependiendo del estado del paciente puede usarse como monoterapia, asociada a otro antidiabético oral o combinada con insulina o análogos de GLP1 $1^{10,21,22}$.

Si bien hay claridad acerca de la importancia y los efectos benéficos de incluir la metformina en el esquema farmacológico de estos pacientes, surge el interrogante sobre el momento ideal para iniciar tratamiento. Es bien conocido que la dieta y los cambios en el estilo de vida pueden por sí solos disminuir los niveles de glucemia hasta cierto punto ${ }^{23}$; Algunas investigaciones plantean cuándo se debe iniciar una terapia farmacológica con metformina en estos pacientes, como es el caso de la investigación 
realizada por Romanelli et al, quienes compararon el inicio de terapia con metformina en los primeros seis meses de diagnóstico de $\mathrm{DM} 2$ versus inicio tardío, posterior a seis meses del diagnóstico, el inicio temprano de este fármaco se asoció a disminución mayor en los niveles de hemoglobina glicosilada y, a su vez, mayor posibilidad de alcanzar valores iguales o menores a 7\%, asociado a mayor reducción en el índice de masa corporal ${ }^{24}$. Asimismo, se ha demostrado que el inicio temprano de la terapia farmacológica y control estricto de la glucemia se asocian a mejoría a corto plazo en la función de la célula beta, aunque esta declina con el tiempo ${ }^{25}$. Es claro que un estricto control glucémico se asocia a menores complicaciones microvasculares a largo plazo ${ }^{10,26,27}$, sin embargo, la relación con las complicaciones macrovasculares es menos clara, no hay evidencia suficiente para asegurar que un control adecuado de la glucemia puede prevenir el desarrollo en complicaciones macrovasculares, enfermedad coronaria, enfermedad cerebrovascular y enfermedad arterial periférica ${ }^{10,28}$; pero, se ha descrito en los últimos años la asociación entre la metformina y reducción del riesgo cardiovascular a través de reducción en niveles de lípidos y ralentización del crecimiento del grosor de la íntima media ${ }^{28,29}$. Por tanto, dada la importante morbimortalidad de las complicaciones macrovasculares, el hecho de que la metformina pueda prevenir su desarrollo, es una clara indicación para terapia temprana con este medicamento.

\section{PREDIABETES}

La evidencia sugiere que las complicaciones crónicas de la DM2, empiezan a desarrollarse durante el estado de prediabetes ${ }^{10}$; la prevalencia de retinopatía, microalbuminuria y neuropatía están presentes en esta población en un 8 a 19\%, 5 a 15\% y $45 \%$, respectivamente $\mathrm{e}^{30-35} \mathrm{y}$, asimismo, la ADA, afirma que riesgo de enfermedad cardiovascular es dos a tres veces mayor en pacientes con prediabetes que en la población general ${ }^{36-38}$. Por esta razón, la ADA en las últimas guías recomienda cambios en el estilo de vida, que incluyen dieta con reducción de $7 \%$ del peso y ejercicio aeróbico 150 minutos a la semana?. Esta estrategia disminuye el riesgo de progresión a $\mathrm{DM} 2$ en $58 \%$ a tres años ${ }^{39}$. La ADA, también sugiere inicio de terapia con metformina para evitar la progresión a prediabetes, principalmente en pacientes con obesidad severa, mujeres con antecedente de diabetes gestacional y aquellos pacientes con hemoglobina glicosilada más cercana al rango de diabetes7, ya que el uso de este medicamento en pacientes prediabéticos reduce en un 31\% el riesgo de progresar a DM2 en tres años ${ }^{39}$.

\section{DIABETES MELLITUS TIPO I}

La Sociedad Americana de Pediatría recomienda el uso de metformina como primera línea en pacientes niños y adolescentes con diagnóstico de $\mathrm{DM} 2^{40}$. Sin embargo, el uso de antidiabéticos orales en la DM1 es controversial y las biguanidas no están oficialmente recomendadas. Con el aumento en la prevalencia de la obesidad en niños y adolescentes, la resistencia a la insulina se hace cada vez más frecuente en los pacientes con DM1, durante la pubertad este fenómeno se incrementa y los pacientes pueden incluso desarrollar síndrome metabólico, lo que obliga a aumentar los requerimientos de insulina, pero, también con los efectos deletéreos que esto implica. Según este principio fisiopatológico, el uso de metformina podría ser beneficioso en los pacientes niños y adolescentes con DM1 con sobrepeso u obesidad que desarrollen resistencia a la insulina ${ }^{8}$.

\section{OVARIO POLIQUÍSTICO}

Aunque la fisiopatología es pobremente entendida, la mayoría de las mujeres con Síndrome de Ovario Poliquístico (SOP) tienen resistencia a la insulina, independientemente del peso ${ }^{41}$. La resistencia a la insulina y la hiperinsulinemia secundaria juegan un papel importante en esta patología: se asocian a la producción excesiva de andrógenos y anovulación secundaria42. En Estados Unidos, la prevalencia de $\mathrm{DM} 2$ es dos veces mayor en las mujeres jóvenes con SOP que en la población normal y el mecanismo fisiopatológico por el que esto ocurre es la resistencia a la insulina que presentan las pacientes ${ }^{43}$. El efecto de la metformina en prevenir la progresión a DM2, puede extrapolarse en las pacientes con este síndrome.

La metformina mejora la resistencia a la insulina en estas pacientes, además, disminuye el riesgo cardiovascular asociado; también, puede disminuir el nivel circulante de andrógenos, incluso mejorando el hirsutismo y mejora los ciclos menstruales, retornando la ovulación ${ }^{44}$.

\section{OBESIDAD Y RIESGO CARDIOVASCULAR}

\section{Obesidad}

Debido a la frecuente asociación entre la obesidad y la $\mathrm{DM} 2$, y tras la mejoría tanto del control glucémico, 
como del peso con el empleo de metformina a corto plazo, se ha planteado el efecto exclusivo de las biguanidas sobre el control del peso. Las primeros reportes, que demostraron dichos efectos, provienen del sub-análisis del estudio Diabetes Prevention Program ${ }^{45}$; no obstante, solo recientes investigaciones han dilucidado el modelo molecular subyacente, el cual se correlaciona con la modulación de la vía de la AMPK, junto a la modulación del sistema humoral de adipoquinas, disminución de la leptina y aumento de la adiponectina, generando así un estado anorexígeno ${ }^{46,47}$.

Ante tal evidencia, estudios prospectivos y de meta-análisis dan soporte a la asociación entre metformina y la reducción de peso, con resultados no concluyentes por la gran heterogeneidad y dificultades metodológicas de los estudios. Asimismo, los efectos en la reducción del peso han sido inferiores a los producidos por los cambios en el estilo de vida o medicamentos aprobados para la reducción de peso ${ }^{48,49}$; aunque algunos subgrupos presentan una mayor reducción de peso con el uso de metformina, tales como mujeres obesas en edad fértil con SOP ${ }^{51}$, niños y adolescentes con sobrepeso u obesidad, con mejor beneficio en el subgrupo de pacientes con resistencia a la insulina calculado por el índice Homeostasis Model Assessment, índice indirecto de insulinorresistencia ${ }^{52}$. Además, como protector en la ganancia de peso o como tratamiento de la misma, secundario a terapia con anti-psicóticos atípicos de segunda generación bien conocidos por sus efectos adversos cardiovasculares ${ }^{53,54}$.

Los programas de prevención primaria de Estados Unidos, dan recomendaciones débiles respecto al uso de la metformina en estos programas para la reducción del peso en los pacientes obesos y con sobrepeso ${ }^{48}$, permitiendo abrir caminos para futuras investigaciones que promuevan el uso de dicha molécula, tras evidencia que respalde su efectividad.

\section{Riesgo cardiovascular}

Las complicaciones microvasculares se encuentran relacionadas con el grado, variabilidad y el tiempo de exposición a hiperglucemia, por ello, el control glucémico como objetivo temprano se ha asociado a disminución en la incidencia de estas ${ }^{55-57}$. En la cohorte con DM1 del Diabetes Complications and Control Trial, el control glucémico se asoció con una reducción estadísticamente significativa en la incidencia de complicaciones crónicas (Ver Tabla
1). Sin embargo, en el seguimiento de la misma cohorte, The Epidemiology of Diabetes Intervention and Complications ${ }^{56}$ evidenció una mayor incidencia de complicaciones entre los pacientes que habían recibido inicialmente terapia estándar comparada con terapia intensiva, aún después de haber pasado varios años de modificada la terapéutica del primer grupo a intensiva.

Tabla 1: Hallazgos del estudio Epidemiology of Diabetes Intervention and Complication (EDIC).

\begin{tabular}{|l|c|}
\hline \multicolumn{1}{|c|}{$\begin{array}{c}\text { Complicaciones } \\
\text { (años de seguimiento) }\end{array}$} & $\begin{array}{c}\text { \% de reducción } \\
\text { en grupo con } \\
\text { tratamiento } \\
\text { intensivo }\end{array}$ \\
\hline \multicolumn{2}{|c|}{ Retinopatía Diabética (10 años EDIC) } \\
\hline Progresión de retinopatía & 24 \\
\hline $\begin{array}{l}\text { Progresión a Retinopatía } \\
\text { proliferativa }\end{array}$ & 59 \\
\hline \multicolumn{2}{|c|}{ Nefropatía Diabética (8 años EDIC) } \\
\hline Microalbuminuria de novo & 59 \\
\hline Albuminuria clínica & 84 \\
\hline \multicolumn{2}{|c|}{ Neuropatía (8 años EDIC) } \\
\hline Síntomas & 51 \\
\hline Signos & 43 \\
\hline \multicolumn{2}{|c|}{ Enfermedad cardiovascular (17 años DCCT + } \\
EDIC) \\
\hline $\begin{array}{l}\text { Cualquier tipo } \\
\text { muerte por enfermedad } \\
\text { cardiovascular }\end{array}$ \\
\hline $\begin{array}{l}\text { Infarto no fatal del } \\
\text { miocardio, enfermedad }\end{array}$ \\
\hline
\end{tabular}

Fuente: Adaptado de Ranjit IR et al. J Assoc Physicians India 2011; 59: 8 -12 (48)

De igual forma, en el United Kingdom Prospective Diabetes Study ${ }^{58}$ se evidenció que a pesar de tener índices de aumento de la glucemia similares, los individuos que presentaban valores de glucosa plasmática en ayunas más bajos en el momento del diagnóstico presentaron menos complicaciones vasculares y menores resultados clínicos adversos que los individuos con valores de glucemia más altos, es decir, a pesar del adecuado control metabólico logrado y de similares valores glucémicos, las diferencias persistieron a lo largo del tiempo siendo mayor los eventos vasculares en el grupo de paciente con valores glucémicos elevados (Ver Tabla 2). A lo anterior, los autores denominaron al fenómeno 
como “Memoria Metabólica” o “Efecto del Legado”, en donde el entorno hiperglucémico celular inicial se mantiene impreso en las células del endotelio vascular. Por lo que el control metabólico temprano es importante en el sostenimiento de los beneficios aportados por la terapia.

Tabla 2. Cambio del riesgo por la metformina en patología micro y marcovascular.

\begin{tabular}{|l|l|l|}
\hline \multirow{2}{*}{} & \multicolumn{2}{|c|}{ Cambio en el riesgo } \\
\cline { 2 - 3 } & \multicolumn{1}{|c|}{ Metformina } & $\begin{array}{l}\text { Sulfunilurea/ } \\
\text { insulina }\end{array}$ \\
\hline $\begin{array}{l}\text { Algún evento } \\
\text { relacionado con } \\
\text { diabetes }\end{array}$ & $\downarrow 32 \% \mathrm{p}=0.002$ & $\downarrow 7 \%$ (NS) \\
\hline $\begin{array}{l}\text { Mortalidad } \\
\text { relacionada con } \\
\text { diabetes }\end{array}$ & $\downarrow 42 \% \mathrm{p}=0.017$ & $\downarrow 20 \%$ (NS) \\
\hline $\begin{array}{l}\text { Mortalidad por } \\
\text { cualquier causa }\end{array}$ & $\downarrow 36 \% \mathrm{p}=0.011$ & $\downarrow 8 \%$ (NS) \\
\hline $\begin{array}{l}\text { Infarto del } \\
\text { miocardio }\end{array}$ & $\downarrow 39 \% \mathrm{p}=0.010$ & $\downarrow 21 \%$ (NS) \\
\hline $\begin{array}{l}\text { Complicación } \\
\text { Microvascular }\end{array}$ & $\downarrow 29 \%$ (NS) & $\downarrow 16 \%$ (NS) \\
\hline
\end{tabular}

NS: No significativo. $\downarrow$ : Reducción

Fuente: Adaptado de: Bailey C.J Cardiovasc Drugs Ther 2008; 22: 215-224 (55).

El fenómeno de memoria metabólica tiene su principal base fisiológica en el estrés oxidativo y la glucosilación de proteínas mitocondriales, con la participación del Factor Nuclear kappa Beta (NF-k $\beta)^{55}$, NAPH oxidasa ${ }^{59}$, deacetilasa de Histona Clase III sirtuin 1 (SIRT1) en la vía del $\mathrm{AMPK}^{60}$ y del gen proapoptótico BAX, documentándose la inhibición de estas vías por parte de la metformina y, por lo tanto, la modificación de la memoria metabólica celular (Ver Figura 1 y 2$)^{61}$.

El NADPH generado del metabolismo de la glucosa, a través de la vía pentosa fosfato, juega un papel importante en el estrés oxidativo a través de la reducción del peróxido de hidrogeno que es facilitado por el sistema del glutatión ${ }^{62}$ (Ver Figura 1). Asimismo, la NADPH es oxidada a aniones superóxidos mediante la enzima NADPH Oxidasa, que al catalizar la oxidación del NADPH bloquea la vía del glutatión y aumenta la producción de agentes oxidantes. Tal enzima es favorecida por el NF-k $\beta$, cuya expresión se encuentra aumentada en estado hiperglucémico ${ }^{63,64}$. Adicionalmente, el exceso de aniones superóxido reacciona directamente con el Óxido Nítrico (ON) en consecuencia lo atenúa y reduce la eficacia de este sistema vasodilatador potente de la célula endotelial y homeostasis de los vasos sanguíneos, asimismo, la reacción entre superóxido y el ON produce un oxidante potente, el Anión de Peroxinitrito (ONOO), un citototóxico que lesiona directamente la célula endotelial, disminuye la bioactividad del ON y favorece la síntesis de mediadores inflamatorios mediante aumento en la expresión, de la Ciclooxigenasa2 (COX2) y disminución de la sintasa de Prostaciclina (PGI2) ${ }^{65}$. El ONOO es cuantificado indirectamente a través de la 3-nitrotirosina, éste último se encuentra elevado significativamente en pacientes con diabetes, evidenciando así aumento del $\mathrm{ONOO}^{66}$ (Ver Figura 2).

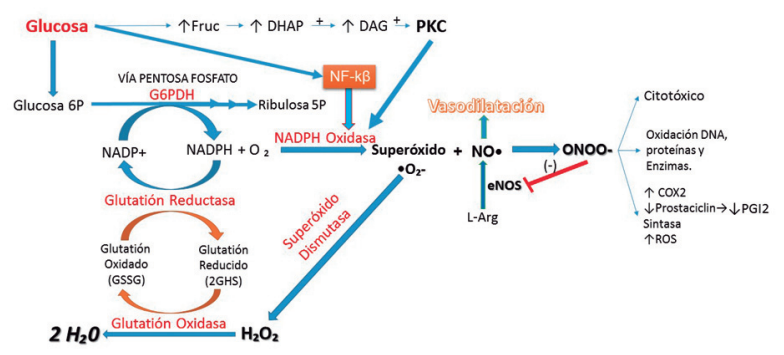

Figura 2: Relación entre glucosa y estrés oxidativo.

(Fruc: Fructosa DHAP: Dihidróxiacetona Fosfato DAG: Diacilglicerol PKC: Protein Kinasa C. G6PDH: Glucosa 6 fosfato deshidrogenasa NF-KB: Factor Nuclear KB. NO: Óxido Nítrico)

Durante el metabolismo de la glucosa, se genera NADPH en la vía de la pentosas fosfatos, el cual favorece la reducción del glutatión a través de la enzima Glutatión Reductasa, con lo que se cataliza la conversión de peróxido de hidrógeno en 2 mol de agua, disminuyendo así el estado oxidativo, sin embargo, la NAPDH Oxidasa favorece la vía del NAPDH hacia la formación de superóxido que lesiona el endotelio vascular y previniendo la vasodilatación.

Fuente: autores.

Por otro lado, la glicosilación de proteínas mitocondriales acompañadas del exceso de Especies Reactivas de Oxígeno (ROS) en respuesta a la hiperglucemia, también se ha asociado a la generación de complicaciones en la DM2. El mecanismo por el cual la hiperglucemia induce exceso en la formación de ROS a nivel mitocondrial parece estar relacionado con la $\mathrm{SIRT}_{1}$ que es un proteína involucrada en la respuesta ante el estrés, cuya expresión y actividad es regulada por la disponibilidad de nutrientes, y su función es modular la respuesta adaptativa a la restricción calórica y los estados inflamatorios, mediante la activación del Receptor Activado de Proliferación de los Peroxisomas (PPAR- $\alpha$ ) e inhibición del NF-k respectivamente, esta proteína se encuentra suprimida en $\mathrm{DM}_{2}$ y obesidad ${ }^{67}$, supresión que persiste aún después de normalizado el medio glucémico ${ }^{60}$. 
Asímismo, la SIRT1 induce la expresión de LKB1 y AMPK favoreciendo así la gluconeogénesis y lipólisis, que al igual que las anteriores, también se encuentran bloqueadas en la DM2, perpetuando así los cambios genéticos, metabólicos e inflamatorios presentes en la memoria metabólica, por lo que se considera que la SIRT1 juega un papel importante en este fenómeno (Ver Figura 3). Por ello se ha estudiado el posible efecto de la metformina sobre esta proteína, encontrando una acción inhibitoria sobre el bloqueo en la expresión de la SIRT1 y en la actividad de LKB1 y AMPK luego de cuatro semanas de tratamiento, actuando así sobre la memoria metabólica ${ }^{60}$.

De la misma forma, la AMPK tiene como dos de sus objetivos claves la Acetil-Coa Carboxilasa (ACC)-y la 3-hidroxi-3-metilglutaril-CoA reductasa, enzimas claves en la síntesis de ácidos grasos y colesterol, respectivamente, por lo que su efecto final será la inhibición de estas dos vías ${ }^{64,68}$. Adicionalmente, la AMPK también es activada por fosforilación de otras dos quinasas, la LKB1 y la proteína quinasa dependiente de $\mathrm{Ca2+/calmodulina.} \mathrm{Es} \mathrm{así} \mathrm{como}$ un alteración, ya sea por acetilación de la LKB1 o disminución en la actividad fosforilizadora de la AMPK, afectará negativamente la vía LKB1/AMPK/ ROS que es regulada por la SIRT1, siendo este otro mecanismo asociado al fenómeno de memoria metabólica (Ver Figura 3).

En conclusión, la AMPK es activada por el estrés metabólico para promover la conservación de energía y la captación de glucosa, permitiendo la sobrevida celular en estados de bajo aporte calórico. El efecto de la metformina sobre ello es visible clínicamente, ya que su uso reduce eventos cardiovasculares y demás complicaciones macrovasculares en el paciente con DM2 (Ver Tabla 2) ${ }^{6}$.

\section{Protección vascular, inflamación y hemostasia}

Otro mecanismo por lo cual la metformina otorga beneficio adicional en el paciente con diabetes mellitus es la protección vascular. El medio hiperglucémico favorece el aumento en la producción de fibronectina y colágeno en las células endoteliales generando aumento del grosor de la pared del vaso, hallazgo que fue descrito en células endoteliales de venas umbilicales humanas, en donde se demostró que la sobreexpresión de la fibronectina se encuentra inducida por niveles altos de glucosa y que ésta no era fácilmente reversible después de la exposición a niveles normales del carbohidrato, generando además prolongación en la inducción de PKC- $\beta$ (Protein Kinasa C- $\beta$ ), NADPH oxidasa, colágeno y fibronectina ${ }^{69}$. La metformina parece modificar este efecto mediante la inhibición del, Factor de Crecimiento Transformante Beta 1 (TGF- $\beta 1$ ) con lo cual se bloquea la diferenciación del miofibroblasto y la matriz extracelular dependientes de TGF- $\beta 1^{70}$. Esta acción le adiciona otro potencial beneficio a la metformina, la modulación de inflamación en la fibrosis pulmonar idiopática asociada a bleomicina ${ }^{71}$. Al disminuir la expresión de colágeno y fibronectina se reduce el grosor de la pared del vaso, es así como a través de distintos estudios se ha observado la disminución en el grosor de la Íntima Media (IMT) en especial el de la Carótida (CIMT) posterior a un año de tratamiento con metformina ${ }^{72}$. En un estudio prospectivo, se evidenció que la metformina a dosis de 500 a 750 mg/día atenuaba la progresión del IMT carotideo a los dos años de tratamiento ${ }^{72}$; hallazgos similares fueron descritos en la cohorte de tres años de pacientes diabéticos en donde el cambio anual en cIMT promedio del grupo de glibenclamida y metformina $(0,003+/-0,048 \mathrm{~mm})$ fue menor que la del grupo de glibenclamida $(0,064+/-0,045 \mathrm{~mm})$ y el grupo gliclazida $(0,032+/-0,036 \mathrm{~mm})(p<0,0001$ y $p=0,043$ respectivamente $)^{73}$. Tales hallazgos, además de ser soportados por la modificación en el colágeno y la fibronectina, también pueden ser explicados debido a la acción de la metformina al inhibir la proliferación de células del músculo liso aórtico, la expresión de metaloproteinasa de matriz ${ }^{74}$ tipo-2 y producción de ROS, a través de la inhibición de la NADPH oxidasa y Protein Kinasas $C$ que suprime el efecto de la leptina sobre la producción de ROS. Sin embargo, en el estudio The investigators of the Carotid Atherosclerosis: Metformin for insulin ResistAnce) tal beneficio no se observó en población sin DM2.

Adicionalmente, la metformina tiene acción en la modificación de procesos aterogénicos como lo son la lesión endotelial e inflamación. El primero se presenta dado que la AMPK que se incrementa en respuesta al estrés, como en el infarto agudo de miocardio, hipertensión arterial y diabetes, fosforila la sintasa de oxido nítrico endotelial ${ }^{75}$ estimulando así la producción de $\mathrm{ON}$, que conlleva finalmente a un proliferación vascular y vasodilatación ${ }^{75}$. En cuanto al efecto antiinflamatorio, la metformina regula este proceso a través de la inhibición en la expresión de moléculas de adhesión leucocitaria como ICAM-1 y VCAM-1, vía AMPK, adicionalmente disminuye la expresión del NF-kB. 


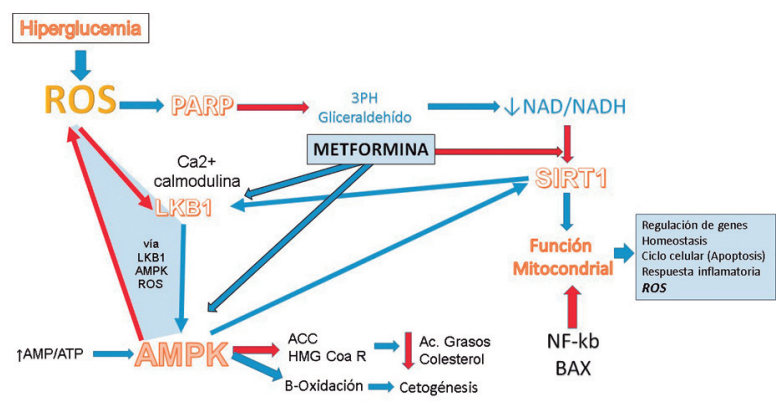

Figura 3: Vía de la LKB1/AMPK/ROS, Metformina y Memoria Metabólica.

(Rojo: Vías Inhibitorias. Azul: Vía Estimulatoria. ROS=Especies Reactivas de Oxigeno, $\mathrm{PARP}=\mathrm{ADPribose}$ polimerasa, $3 \mathrm{PH}=$ gliceraldehido 3 Fosfato Deshidrogenasa, NAD=nicotinamida adenina dinucleótido, NADH = NAD Reducido, SIRT 1= Deacetilasa de Histona Clase III sirtuin 1, AMPK= Proteín quinasa activada por AMP, ACC = Acetil-Coa Carboxialasa, HMGCoa $R=3$ - hidroxi - 3 metilglutaril - CoA reductasa. NF kb= Factor Nuclear Kappa Beta). La hiperglucemia induce formación de ROS, estos producen daño en el DNA que inicia la activación de la PARP que inhibe la formación de Gliceraldehido 3 fosfato reduciendo así la relación NAD/NADH que inhibe la SIRT1 bloqueando así la función mitocondrial e induciendo la apoptosis, de igual forma estas ROS estimulan la respuesta inflamatoria a través de la transcripción citoquinas mediadas por FN-KB como el factor de necrosis tumoral, que provoca la migración de la proteína NF-KB que incrementa la producción de TNF y otras citoquinas, favoreciendo así un mayor estado inflamatorio y alteración en la función mitocondrial generando alteración en la expresión génica, en la homeóstasis y muerte celular programada. Por otro lado, las ROS, inhiben la LKB1 bloqueando su estimulo sobre la lipólisis. La Metformina ejerce su efecto en la memoria metabólica, al inhibir el bloqueo en la expresión de la SIRT1 y en la actividad de LKB1 y AMPK.

Fuente: autores

Por otro lado, la metformina reduce la expresión del factor de von Willebrand, el activador tisular del plasminógeno, el inhibidor-1 del activador del plasminógeno ${ }^{76}$, del factor VII y XIII; lo que otorga un efecto antitrombótico ${ }^{63,64}$. Adicionalmente, regula la elevación de la prostaglandina $\mathrm{F}_{2} \mathrm{a}^{77}$, ácidos grasos libres y mantiene un adecuado balance oxidoreducción vascular con el aumento en la expresión de la superóxido dismutasa, enzima del sistema NAPH Oxidasa, generando finalmente una mejor función vasodilatadora. Por lo anterior, y como ventaja adicional, Tousoulis et $a^{78}$, evidenciaron que la combinación de metformina $850 \mathrm{mg} / \mathrm{d}$ con atorvastatina $10 \mathrm{mg} / \mathrm{d}$ por seis semanas mejoraba la dilatación dependiente de endotelio $(p<0.01)^{78}$. Resultados que fueron consistentes en población sana en el estudio de Zhang et al.79, sin embargo, la lesión endotelial por reperfusión, no parece prevenirse en población sin $\mathrm{DM}_{2}{ }^{80}$.

\section{Control Lipídico}

La síntesis de ácidos grasos es regulada por la ACC, la cual es una enzima que utilizando como cofactor la biotina, adiciona de manera irreversible un grupo bicarbonato al acetil-CoA para producir
malonil-CoA siendo este último el sustrato para la síntesis de ácidos grasos ${ }^{81}$. En modelos animales, la ACC es fosforilada por la acción de la AMPK, tal efecto generaría un beneficio hipolipemiante de la metformina (Ver Figura 2). Adicionalmente, aumenta la recaptación de lipoproteinas de muy baja densidad (LDL), aumenta la lipólisis intracelular y la subsecuente oxidación en la mitocondria ${ }^{82}$, además, modifica el ciclo circadiano de la expresión de genes del metabolismo graso ${ }^{83}$. Sin embargo, el descenso en los triglicéridos a lo largo de distintos estudios no ha sido significativo.

Por otro lado, la proteína $A B C 1^{84}$, transportador responsable del $70 \%$ del eflujo de colesterol desde los macrófagos espumosos hacia las apo A-I, es incrementado por la activación de la AMPK principalmente en arterias ateroscleróticas, modificando así los niveles de colesterol y protegiendo el endotelio vascular de la $L^{2} L^{85}$. Pentikainen et al., documentaron en pacientes con hiperlipidemia tipo IIB un descenso en colesterol total del $8,1 \%(p<0.05)$ y LDL del $9,6 \%$ posterior a nueve semanas de tratamiento con metformina $2 \mathrm{~g} / \mathrm{día}^{86}$. Además, Diehl et al. Evidenciaron que el tratamiento con metformina durante seis meses aumentó el colesterol HDL3 y redujo la grasa truncal en población no diabética con lipodistrofia asociada a Virus de Inmunodeficiencia Humana (de $21 \mathrm{mg} / \mathrm{dL}$ a $24 \mathrm{mg} / \mathrm{dL}, \mathrm{p}=0.002)^{87}$, mostrando así, un posible control lipídico en población no diabética.

\section{Cardiopatía}

En concordancia con lo anterior, diferentes estudios animales $^{88}$ y humanos retrospectivos de grandes bases de datos han evidenciado que la metformina puede reducir los eventos cardiovasculares. Ejemplo de los anterior, Evans et al. usando los registros The Diabetes Audit Research In Tayside Scotland ${ }^{89}$ y Medicines Monitoring Unit, analizaron más de 5700 registros de pacientes, encontrándose una menor incidencia de mortalidad general y mortalidad cardiovascular a cinco años entre los pacientes que usaron metformina como monoterapia inicial comparado con aquellos con sulfunilurea (RR ajustado: 1,43 (95\% IC: $1,15-1,77$ ) y 1,70 (95\% IC: $1,18-$ $2,45)$ ), respectivamente) e incluso con el grupo de pacientes que iniciaron con metformina y se modificó a sulfunilurea (RR ajustado: 2,47 (95\% IC: 1,88-3,25) y $2,29$ (95\% IC: $1,45-3,61)$ ), respectivamente ${ }^{89}$.

Por otro lado, se estima que la incidencia de falla cardiaca en población con DM2 es entre 2,3 y 2,5 veces 
mayor que en población sin DM2 y se ve reducida con el uso de metformina90,91.

En el estudio realizado por miembros del centro Kaiser Permanente Northwest, el uso de metformina asociado a dieta y ejercicio mostró una reducción en la tasa de incidencias de falla cardiaca comparada con sulfunilurea (razón de tasas $=0,48$, $\mathrm{p}=0,016)^{91}$. Además, se asocia a disminución en los niveles de N-terminal Pro-Péptido Natriurético Cerebral disminuyendo la prevalencia de valores superiores a $200 \mathrm{pg} / \mathrm{mL}$. OR=0,36 (IC 95\%=0,18$0,70, p=0,003)^{92}$.

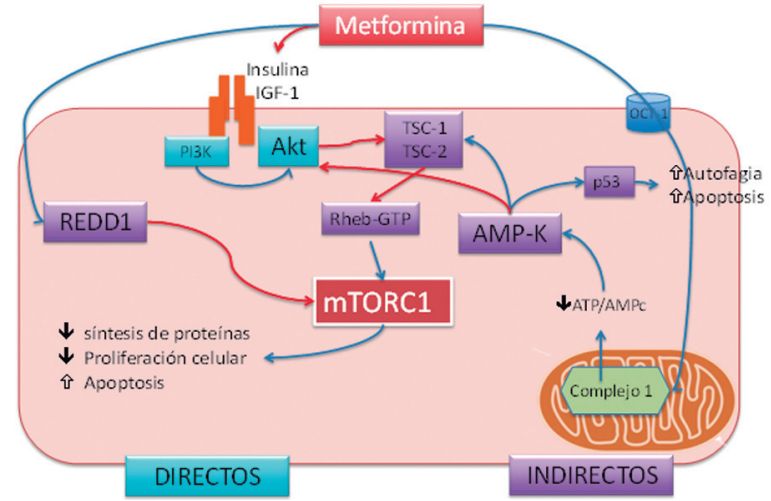

Figura 4: Mecanismo regulador de la metformina y su efecto antineoplásico.

(Diagrama esquemático del efecto antineoplásico de la metformina. A nivel sistémico, la metformina reduce los niveles de insulina e IGF-1 que son conocidos por su efecto anabólico y mitogénicos; a su vez, bloquea el efecto de la señalización intracelular PI3K-AktmTORC1 del receptor de dichas hormonas, este hace parte de los mecanismos directos o dependientes de insulina (cuadros en verdeazul)

A nivel celular, los mecanismos indirectos o independientes de insulina (cuadros en morado), son explicados por el transporte del canal OCT1 transportada hasta la mitocondria donde produce una inhibición de la cadena respiratoria mitocondrial sobre el complejo 1 al igual que en su efecto anti-hiperglucemiante. Como se expuso, la razón ATP/AMP disminuye y este produce la activación del AMP-K; por medio de este intermediario se produce la fosforilacion del TCS12, el cual activo inhibe la Rheb-GTP principal activador del mTORC1 lo cual se traduce en su inhibición, tal inhibición es la que explica la disminución de la apoptosis, la proliferación celular y aumento de la apoptosis celular. Tal mecanismo ha sido descrito en diversas clases de células tumorales. También, el AMP-K induce la autofagia y el aumento de la apoptosis vía reguladores del ciclo celular (p53). Otro mecanismo indirecto consiste en la inhibición directa del mTORC1 mediado por la activación de las Rag GTPasas (REDD1).

Fuente: Tomado y modificado de Shaw RJ. Acta Physiol (Oxf). 2009;196(1):65-80 y Dowling RJ, Cancer Res. 2007;67(22):10804-12.

Los efectos fisiológicos descritos anteriormente podrían explicar la protección cardiaca ante eventos isquémicos con posterior mejoría de la función ventricular en población con $\mathrm{DM}_{2}$ o con síndrome metabólico; sin embargo, en pacientes con DM2, estudios han arrojado datos no satisfactorios. Mientras que en modelos animales tal beneficio parece estar presente ${ }^{88,93-95}$ mediante un mecanismo antiapoptótico selectivo ${ }^{96}$.
El estudio The Glycometabolic Intervention as Adjunct to Primary Coronary Intervention in ST-Segment Elevation Myocardial Infarction ${ }^{97}$ no encontró mejoría de la función ventricular a cuatro meses en pacientes con infarto agudo con ST sometidos a intervención percutánea, lo anterior, dado que no se encontró diferencia en el propéptido natriurético cerebral $\mathrm{N}$-terminal (NT-proBNP) ni en la fracción de eyección ventricular izquierda medida por resonancia magnética. Sin embargo, otros autores ${ }^{98,99}$ reportaron una reducción en la incidencia y gravedad de isquemia miocárdica periprocedimiento en pacientes con síndrome metabólico sometidos a Intervención Coronaria Percutánea $(\mathrm{PCI})$, lo anterior dado que los pacientes con metformina presentaron menor elevación de enzimas cardiacas, CK-MB (14,5 vs. $32,9 \%, p=0.008)$ y Troponina I $(14,5$ vs. $34,2 \%, p=$ 0.005). Además, el uso de metformina proporcionó estos efectos beneficiosos sin inducir acidosis láctica por lo que su uso podría no ser suspendido antes de la $\mathrm{PCl}$, y por el contrario, suspendelas podría conducir a efectos deletéreos sobre el control glucémico y aumentar el riesgo cardiovascular, generando así un mayor riesgo en la $\mathrm{PCI}^{98,99}$.

\section{CÁNCER}

Análisis observacionales retrospectivos han develado la asociación entre la diabetes mellitus y cáncer de los sistemas genitourinario, tejido mamario, hepatobiliar, gastrointestinal, entre otros $^{100}$; así como mayor morbimortalidad, riesgo de complicaciones y menor respuesta al tratamiento dirigido al cáncer ${ }^{101}$. Las hipótesis plantean un efecto secundario del hiperinsulinismo y la resistencia a la insulina, dado por la actividad mitogénica directa de esta, así como, por el aumento del Factor de Crecimiento Similar a la Insulina- tipo 1 y tipo 2 al aumentar la expresión del receptor de hormona de crecimiento en células malignas de tejido hepático, mamario, próstata y líneas celulares hemáticas ${ }^{102,103}$, a su vez, como marcador del potencial invasivo y antiapoptótico. Además, la hiperglucemia, si bien, bajo la "hipótesis de Warburg"104, es el principal sustrato metabólico para la generación de energía en las células cancerígenas ${ }^{105,106}$.

Se ha demostrado una reducción de la incidencia a largo plazo de la aparición de neoplasias en los pacientes que tenían tratamiento con metformina, sin correlación con otras terapias como insulina, sulfonilureas, análogos GLP-1 e inclusive, aumento de la incidencia con algunas de estas ${ }^{107-110}$; por lo cual 
abrió el panorama del estudio ante el posible efecto anti-neoplásico de la metformina

La primera evidencia del potencial efecto antineoplásico de la metformina fue reportado por Evans et al., en el 2005, en una cohorte de más de 10000 pacientes con $\mathrm{DM} 2$, en la cual la terapia con metformina se asoció con una reducción del riesgo global de cáncer (OR 0,79; IC 95\% 0,67 a 0,93) ${ }^{111}$. Posteriores análisis observacionales retrospectivos mostraron una similar asociación con el cáncer colorrectal, gástrico, esofágico, hepático, pancreático, de próstata y de mama en pacientes con $\mathrm{DM} 2^{112}$; ensayos in vitro con dosis terapéuticas de metformina (5 a $20 \mathrm{mmol} / \mathrm{L}$ rango celular), demuestran, a corto plazo, cambios histopatológicos y moleculares reversibles de células neoplásicas en modelos tanto en humanos como murinos y primates ${ }^{113}$.

\section{Mecanismos anticancerígenos de la metformina}

De los mecanismos previamente comentados, los efectos antineoplásicos comparten una vía común con las vías moleculares anti-hiperglucemiantes, divisibles en aquellas dependientes o independientes de la insulina (Ver Figura 4); respecto a las primeras, se ha evidenciado reducción de los niveles circulantes del factor de crecimiento similar a la insulina- tipo 1 e insulina, a través de la modulación de la actividad intracelular de sus receptores, a través de la vía de señalización de la Proteína cinasa B ${ }^{114}$. Por otro lado, y de forma no dependiente de insulina, la activación de la AMPK, como principal determinante en la vía anticancerígena, produce la inhibición de la señalización Phosphatidylinositol-4,5-bisphosphate 3-kinase, AKT y R Mammalian Target of Rapamycin, fundamental en la patogenia de la carcinogénesis ${ }^{115-117}$.

Adicional a los efectos antineoplásicos, también han sido reportadas propiedades anti-metastásicas, al inhibir la angiogénesis, mecanismo pilar del fenómeno de metástasis, al reducir los niveles del factor de crecimiento endotelial vascular tipo 1, Inhibidor Plasmático del Factor activador Plasminógeno 1 (PAI1) , Metalopreinasas de Matriz tipo 2 y tipo $9^{118-121}$, así como el bloqueo del potencial invasivo celular, tras la inversión de la transición mesénquima-epitelio mediado por la inhibición del TGF $\beta^{122,123}$.

De estos efectos independientes previamente referidos, el determinante molecular, como se postula en los efectos insulino-sensibilizantes, es la activación de la LKB1/AMPK; no obstante, se han descrito efectos directos independientes de dicha vía de señalización. A nivel nuclear, se ha demostrado un efecto modulador del ciclo celular a través de la disminución en la expresión de la proteína Ciclina D1, evitando la transición de la fase $\mathrm{G}_{1}$ a la fase $\mathrm{S}^{124}$, evitando la síntesis de ADN y proliferación celular anormal; asimismo, el p53, como principal regulador del ciclo celular es potenciado a través del incremento en el regulador en respuesta al desarrollo y daño de $\mathrm{ADN}^{125}$ y de la expresión de la cinasa dependiente de ciclina 2 favoreciendo la detención de ciclo celular ${ }^{126}$; a su vez, facilita la apoptosis celular por mecanismos dependientes e independientes de $\operatorname{caspasas}^{127,128}$. Por todo lo anterior, la metformina tiene un efecto antineoplásico y antimetastásico al bloquear el ciclo celular, favorecer la apoptosis y tener efecto antiangiogénico, cuyo efecto final es la disminución en la sobrevida de la célula cancerosa.

También se han descrito propiedades inmunomoduladoras por parte de la metformina, al disminuir el desgaste inmunológico de los Linfocitos T CD8+ que infiltran los tumores al regular la producción de citoquinas pro-inflamatorias linterleucina-2, Factor de Necrosis Tumoral alfa (TNFa) e Interferón Gamma (IFN $\gamma)^{129}$.

Otro de los mecanismos en estudio de la metfomina, es su capacidad de aumentar la expresión de micro-ácidos ribonucleicos, genes reguladores endógenos pos-transcripcionales que pueden tener propiedades principalmente como supresores tumorales; la reducción de este, se ha demostrado en el desarrollo de cáncer pancreático, pulmón, próstata y especialmente en mama ${ }^{130}$; de igual forma, se ha evidenciado resensibilización a quimioterapéuticos tras la exposición a la metformina con doxorrubicina ${ }^{131,132}$, letrozole ${ }^{133}$ y placitaxel134, mejorando así la respuesta a la quimioterapia.

\section{Metformina en las distintas neoplasias}

En vista de los descubrimientos moleculares, se ha buscado la correlación clínica de dichos hallazgos en múltiples ensayos clínicos. Tres meta-análisis ${ }^{135-137}$, en pacientes con y sin DM2, con alrededor de un millón de pacientes, reportaron reducción del riesgo de cáncer de próstata y de su recurrencia bioquímica, sin efecto en la mortalidad relacionada con cáncer de próstata, ni de metástasis. Otro meta-análisis ${ }^{138}$ reporta la reducción del riesgo de cáncer de mama entre pacientes con DM2; más recientemente, el estudio METEOR ${ }^{133}$, ensayo clínico fase dos demostró 
la mejor respuesta de la terapia neo-adyuvante en pacientes con cáncer de mama posmenopáusicas con positividad para receptores estrogénicos.

Respecto al carcinoma escamo-celular de cabeza y cuello con el uso de metformina, una revisión sistemática encontró una disminución de la tasa de la recurrencia loco-regional y de metástasis, y aumento de la supervivencia libre de enfermedad tras el uso de metformina ${ }^{139}$. En relación al cáncer de pulmón, aunque con efecto nulo en los expuestos a tabaco, se encontró una reducción del riesgo de cáncer de pulmón, tras el consumo mayor a cinco años de metformina, en relación al adenocarcinoma de pulmón ${ }^{140,141}$; también, efectos benéficos de reducción del riesgo de cáncer de páncreas entre los pacientes diabéticos tratados con metformina a corto y largo plazo ${ }^{142}$.

De este modo, se abre un panorama de la relación en la reducción del riesgo de cáncer asociado al uso de metformina. Si bien, existe gran evidencia que soporta tal hipótesis, hay diversos estudios en controversia a tales hallazgos; lo que puede explicarse por el desconocimiento del verdadero perfil farmacodinámico de la metformina e inclusive, de la fisiopatología de algunos tipos de cáncer, como del medicamento en sí. Sin embargo, quedarán por esclarecer, a través de los estudios clínicos y moleculares, las verdaderas asociaciones fuertes, que a futuro, promuevan el uso de la metformina, no solo en el ámbito del control metabólico y cardiovascular, sino también, en la prevención primaria, y como adyuvante al tratamiento contra el cáncer.

\section{ConClusión}

Pese al largo tiempo desde el descubrimiento de la metformina, el conocimiento de sus efectos farmacodinámicos aún son inciertos y los avances en estos esclarecerán los múltiples efectos benéficos de esta molécula. Si bien, continúa siendo un pilar fundamental en el tratamiento de la DM2, la evidencia muestra un beneficio adicional en esta y otras enfermedades de gran importancia en el ámbito clínico y de salud pública, como el riesgo cardiovascular, al mostrar impacto en la función endotelial, la protección vascular por la antiaterogénesis, el metabolismo lipídico y la función cardiaca; todos estos factores están implicados en los eventos cardiovasculares mayores que generan impacto de morbimortalidad en la era actual. No menos importante y, quizás, con una gran relación con el ambiente proinflamatorio, se muestra la reciente evidencia a favor de la reducción en la incidencia de neoplasias de distinto origen, aún ad portas de conocerse a cabalidad, efecto de gran interés, por la carga en la morbimortalidad, en lo psicosocial y lo familiar si se impactará en la incidencia de estas patologías.

Finalmente, es de gran importancia que el profesional de la salud reconozca las indicaciones y contraindicaciones para insertar su pronto inicio dentro de la terapéutica médica, no sólo con el fin de lograr metas glucémicas sino también reducir la morbimortalidad a través de los múltiples beneficios adicionales otorgados por esta; todo lo anterior, dentro de un tratamiento integral e interdiciplinario de cada paciente y el fortalecimiento de la relación médico-paciente ${ }^{143,144}$.

\section{CONFLICTO DE INTERÉS}

Ninguno declarado por los autores.

\section{Financiación}

Ninguna declarada por los autores.

\section{AgRadeCIMIENTOS}

Agradecemos a la Dra. Análida Elizabeth Pinilla Roa, por su labor como docente e investigadora que inspira a la constante búsqueda del conocimiento, con el fin de encontrar la verdad bajo el método científico; esperamos que continúe fomentando este espíritu investigativo en sus estudiantes.

\section{Referencias Bibliográficas}

1. Centers for Disease Control and Prevention. National Diabetes Statistics Report: Estimates of Diabetes and Its Burden in the United States, 2014. Atlanta, GA: US Department of Health and Human Services; 2014.

2. Zhu M, Li J, Li Z, Luo W, Dai D, Weaver SR, et al. Mortality rates and the causes of death related to diabetes mellitus in Shanghai Songjiang District: an 11-year retrospective analysis of death certificates. BMC Endocr Disord. 2015;15:45.

3. Action to Control Cardiovascular Risk in Diabetes Study G, Gerstein HC, Miller ME, Byington RP, Goff DC, Jr., Bigger JT, et al. Effects of intensive glucose lowering in type 2 diabetes. $\mathrm{N}$ Engl J Med. 2008;358(24):2545-59.

4. Nandy M, Mandal A, Banerjee S, Ray K. A prescription survey in diabetes assessing metformin use in a tertiary care hospital in Eastern India. J Pharmacol Pharmacother. 2012;3(3):273-5.

5. American Diabetes Association. Approaches to Glycemic Treatment. Diabetes Care. 2016;39:S52-9.

6. Triggle CR, Ding H. Cardiovascular impact of drugs used in the treatment of diabetes. Ther Adv Chronic Dis. 2014;5(6):245-68.

7. American Diabetes Association. Standards of medical care in diabetes. Diabetes Care. 2014;37:S14-S80. 
8. Konrad K, Datz N, Engelsberger I, Grulich-Henn J, Hoertenhuber T, Knauth B, et al. Current use of metformin in addition to insulin in pediatric patients with type 1 diabetes mellitus: an analysis based on a large diabetes registry in Germany and Austria. Pediatr Diabetes. 2014: 16(7):529-37

9. Glueck CJ, Fontaine RN, Wang P, Subbiah MT, Weber K, Illig E, et al. Metformin reduces weight, centripetal obesity, insulin, leptin, and low-density lipoprotein cholesterol in nondiabetic, morbidly obese subjects with body mass index greater than 30 . Metabolism. 2001;50:856-61.

10. Pratley RE. The early treatment of type 2 diabetes. Am J Med. 2013;126:S2-9.

11. Stumvoll M, Nurjhan N, Perriello G, Dailey G, Gerich JE. Metabolic effects of metformin in non-insulin-dependent diabetes mellitus. N Engl J Med. 1995;333:550-4

12. Pernicova I, Korbonits M. Metformin--mode of action and clinical implications for diabetes and cancer. Nat Rev Endocrinol. 2014;10(3):143-56.

13. Ferrannini E. The Target of Metformin in Type 2 Diabetes. N Engl J Med. 2014;371:1547-8.

14. Baur JA, Birnbaum MJ. Control of gluconeogenesis by metformin: does redox trump energy charge? Cell Metab. 2014;20(2):197-9.

15. Hundal RS, Krssak M, Dufour S, Laurent D, Lebon V, Chandramouli V, et al. Mechanism by which metformin reduces glucose production in type 2 diabetes. Diabetes. 2000;49(12):2063-9.

16. Rena G, Pearson ER, Sakamoto K. Molecular mechanism of action of metformin: Old or new insights? Diabetologia. 2013;56(9):1898-906.

17. Viollet B, Guigas B, Sanz Garcia N, Leclerc J, Foretz M, Andreelli F. Cellular and molecular mechanisms of metformin: an overview. Clin Sci. 2011;122(6):253-70.

18. Wu T, Thazhath SS, Bound MJ, Jones KL, Horowitz M, Rayner CK. Mechanism of increase in plasma intact GLP-1 by metformin in type 2 diabetes: Stimulation of GLP-1 secretion or reduction in plasma DPP-4 activity? Diabetes Res Clin Pract. 2014;106(1):e3-6.

19. Farilla L, Hui H, Bertolotto C, Kang E, Bulotta A, Di Mario U, et al. Glucagon-like peptide-1 promotes islet cell growth and inhibits apoptosis in Zucker diabetic rats. Endocrinology. 2002;143(11):4397-408

20. Lima MM, Balladares N, Torres C, Vera L, Bognanno F, Marin M, et al. Physiological role of incretins and its importance in type 2 diabetes mellitus. Infor Med. 2009;11(1):437-43.

21. Qaseem A, Humphrey LL, Sweet DE, Starkey M, Shekelle P. Oral pharmacologic treatment of type 2 diabetes mellitus: A clinical practice guideline from the american college of physicians. Ann Intern Med. 2012;156(3):218-31.

22. Bennett WL, Maruthur NM, Singh S, Segal JB, Wilson LM, Chatterjee R, et al. Comparative effectiveness and safety of medications for type 2 diabetes: An update including new drugs and 2-drug combinations. Ann Intern Med. 2011;154(9):602-18.

23. Ryan DH, Espeland MA, Foster GD, Haffner SM, Hubbard VS, Johnson KC, et al. Look AHEAD (Action for Health in Diabetes): design and methods for a clinical trial of weight loss for the prevention of cardiovascular disease in type 2 diabetes. Control Clin Trials; 2003;24(5):610-28.

24. Romanelli RJ, Chung S, Pu J, Nimbal V, Zhao B, Palaniappan L. Comparative effectiveness of early versus delayed metformin in the treatment of type 2 diabetes. Diabetes Res Clin Pract. 2015;108(1):1-9.

25. Kahn SE, Haffner SM, Heise MA, Herman WH, Holman RR, Jones NP, et al. Glycemic durability of rosiglitazone, metformin, or glyburide monotherapy. N Engl J Med. 2006;355:2427-43.

26. No authors. Intensive blood-glucose control with sulphonylureas or insulin compared with conventional treatment and risk of complications in patients with type 2 diabetes (UKPDS 33). UK Prospective Diabetes Study (UKPDS) Group. Lancet. 1998;352(9131):837-53.

27. Ohkubo Y, Kishikawa H, Araki E, Miyata T, Isami S, Motoyoshi S, et al. Intensive insulin therapy prevents the progression of diabetic microvascular complications in Japanese patients with noninsulin-dependent diabetes mellitus: a randomized prospective 6-year study. Diabetes Res Clin Pract; 1995;28:103-17.

28. Scarpello JHB. Improving survival with metformin: the evidence base today. Diabetes Metab. 2003;29(4):6S36-43.

29. Held C, Hjemdahl P, Eriksson SV, Bjorkander I, Forslund L,
Rehnqvist N. Prognostic implications of intima-media thickness and plaques in the carotid and femoral arteries in patients with stable angina pectoris. Eur Heart J. 2001;22(1):62-72.

30. Tapp RJ, Shaw JE, Zimmet PZ, Balkau B, Chadban SJ, Tonkin AM, et al. Albuminuria is evident in the early stages of diabetes onset: Results from the Australian Diabetes, Obesity, and Lifestyle Study (AusDiab). Am J Kidney Dis. 2004;44(5):792-8.

31. Smith AG, Singleton JR. The diagnostic yield of a standardized approach to idiopathic sensory-predominant neuropathy. Arch Intern Med. 2004;164(9):1021-5.

32. Franciosi M, Pellegrini F, Sacco M, De Berardis G, Rossi MCE, Strippoli GFM, et al. Identifying patients at risk for microalbuminuria via interaction of the components of the metabolic syndrome: A cross-sectional analytic study. Clin J Am Soc Nephrol. 2007;2(5):984-91.

33. Kim YI, Kim CH, Choi CS, Chung YE, Lee MS, Lee SI, et al. Microalbuminuria is associated with the insulin resistance syndrome independent of hypertension and type 2 diabetes in the Korean population. Diabetes Res Clin Pract. 2001;52(2):14552.

34. Group DPPR. The prevalence of retinopathy in impaired glucose tolerance and recent-onset diabetes in the Diabetes Prevention Program. Diabet Med. 2007;24(2):137-44.

35. Wong TY, Liew G, Tapp RJ, Schmidt MI, Wang JJ, Mitchell P, et al. Relation between fasting glucose and retinopathy for diagnosis of diabetes: three population-based cross-sectional studies. Lancet. 2008;371(9614):736-43

36. Hu FB, Stampfer MJ, Haffner SM, Solomon CG, Willett WC, Manson JE. Elevated risk of cardiovascular disease prior to clinical diagnosis of type 2 diabetes. Diabetes Care. 2002;25(7):1129-34.

37. Levitzky YS, Pencina MJ, D’Agostino RB, Meigs JB, Murabito JM, Vasan RS, et al. Impact of Impaired Fasting Glucose on Cardiovascular Disease. The Framingham Heart Study. J Am Coll Cardiol. 2008;51(3):264-70.

38. Barr ELM, Zimmet PZ, Welborn TA, Jolley D, Magliano DJ, Dunstan DW, et al. Risk of Cardiovascular and All-Cause Mortality in Individuals With Diabetes Mellitus, Impaired Fasting Glucose, and Impaired Glucose Tolerance. Circulation. 2007;116(2):151-7.

39. Knowler WC, Barrett-Connor E, Fowler SE, Hamman RF, Lachin JM, Walker EA, et al. Reduction in the incidence of type 2 diabetes with lifestyle intervention or metformin. N Engl J Med; 2002;346(6):393-403

40. Copeland KC, Silverstein J, Moore KR, Prazar GE, Raymer T, Shiffman RN, et al. Management of newly diagnosed type 2 Diabetes Mellitus (T2DM) in children and adolescents. Pediatrics. 2013;131(2):364-82.

41. Chang RJ, Nakamura RM, Judd HL, Kaplan SA. Insulin resistance in nonobese patients with polycystic ovarian disease. J Clin Endocrinol Metab. 1983;57(2):356-9.

42. Nestler JE. Metformin for the treatment of the polycystic ovary syndrome. N Engl J Med. 2008;358(1):47-54.

43. Ehrmann DA, Barnes RB, Rosenfield RL, Cavaghan MK, Imperial J. Prevalence of impaired glucose tolerance and diabetes in women with polycystic ovary syndrome. Diabetes Care. 1999;22(1):141-6

44. Sharma ST, Wickham III EP, Nestler JE. Changes in glucose tolerance with metformin treatment in polycystic ovary syndrome: a retrospective analysis. Endocr Pract. 2007;13(4):373-9.

45. Diabetes Prevention Program Research G. Long-term safety, tolerability, and weight loss associated with metformin in the Diabetes Prevention Program Outcomes Study. Diabetes Care. 2012;35(4):731-7

46. Becker S, Dossus L, Kaaks R. Obesity related hyperinsulinaemia and hyperglycaemia and cancer development. Arch Physiol Biochem. 2009;115(2):86-96

47. Rizvi AA, Nikolic D, Sallam HS, Montalto G, Rizzo M, Abate N. Adipokines and lipoproteins: modulation by antihyperglycemic and hypolipidemic agents. Metab Syndr Relat Disord. 2014;12(1):1-10.

48. Leblanc ES, O'Connor E, Whitlock EP, Patnode CD, Kapka T. Effectiveness of primary care-relevant treatments for obesity in adults: a systematic evidence review for the U.S. Preventive Services Task Force. Ann Intern Med. 2011;155(7):434-47.

49. 49.Levri KM, Slaymaker E, Last A, Yeh J, Ference J, D'Amico F, et al. Metformin as treatment for overweight and obese adults: a systematic review. Ann Fam Med. 2005;3(5):457-61. 
50. Nieuwenhuis-Ruifrok AE, Kuchenbecker WK, Hoek A, Middleton P, Norman RJ. Insulin sensitizing drugs for weight loss in women of reproductive age who are overweight or obese: systematic review and meta-analysis. Hum Reprod Update. 2009;15(1):57-68.

51. Bruno RV, de Avila MA, Neves FB, Nardi AE, Crespo CM, Sobrinho AT. Comparison of two doses of metformin (2.5 and 1.5 $\mathrm{g} /$ day) for the treatment of polycystic ovary syndrome and their effect on body mass index and waist circumference. Fertil Steril. 2007;88(2):510-2.

52. McDonagh MS, Selph S, Ozpinar A, Foley C. Systematic review of the benefits and risks of metformin in treating obesity in children aged 18 years and younger. JAMA pediatr. 2014;168(2):178-84.

53. Khan AY, Macaluso M, McHale RJ, Dahmen MM, Girrens K, Ali F. The adjunctive use of metformin to treat or prevent atypical antipsychotic-induced weight gain: a review. J Psychiatr Pract. 2010;16(5):289-96

54. Hasnain M, Fredrickson SK, Vieweg WV. Metformin for obesity and glucose dysregulation in patients with schizophrenia receiving antipsychotic drugs. J Psychopharmacol. 2011;25(6):715-21.

55. Unnikrishnan IR, Anjana R, Mohan V. Importance of Controlling Diabetes Early-The Concept of Metabolic Memory, Legacy Effect and the Case for Early Insulinisation. J Assoc Physicians India. 2011;59Supplement:8-12.

56. Writing Team for the Diabetes C, Complications Trial/ Epidemiology of Diabetes I, Complications Research G. Effect of intensive therapy on the microvascular complications of type 1 diabetes mellitus. JAMA. 2002;287(19):2563-9.

57. Wang PH, Lau J, Chalmers TC. Meta-analysis of effects of intensive blood-glucose control on late complications of type I diabetes. Lancet. 1993;341(8856):1306-9.

58. King P, Peacock I, Donnelly R. The UK prospective diabetes study (UKPDS): clinical and therapeutic implications for type 2 diabetes. Br J Clin Pharmacol. 1999;48(5):643-8.

59. Barreto-Torres G, Soto Hernandez J, Jang S, Rodriguez-Munoz AR, Torres-Ramos CA, Basnakian AG, et al. The beneficial effects of AMP-kinase activation against oxidative stress are associated with prevention of PPARalpha-cyclophilin D interaction in cardiomyocytes. Am J Physiol Heart Circ Physiol. 2015 ;308(7):749-58.

60. Zheng Z, Chen H, Li J, Li T, Zheng B, Zheng Y, et al. Sirtuin 1-mediated cellular metabolic memory of high glucose via the LKB1/AMPK/ROS pathway and therapeutic effects of metformin. Diabetes. 2012;61(1):217-28.

61. Ceriello A. La memoria metabólicainducida por la hiperglucemia: el nuevo reto en la prevención de la enfermedad cardiovascular en la diabetes. Rev Esp Cardiol. 2008;8(C):12-18.

62. Peiro C, Romacho T, Azcutia V, Villalobos L, Fernandez E, Bolanos JP, et al. Inflammation, glucose, and vascular cell damage: the role of the pentose phosphate pathway. Cardiovasc Diabetol. 2016;15(1):82.

63. Bailey CJ. Metformin: effects on micro and macrovascular complications in type 2 diabetes. Cardiovasc Drugs Ther. 2008;22(3):215-24

64. Ewart MA, Kennedy S. AMPK and vasculoprotection. Pharmacol Ther. 2011;131(2):242-53.

65. Lubos E, Handy DE, Loscalzo J. Role of oxidative stress and nitric oxide in atherothrombosis. Front Biosci. 2008;13:5323-44

66. Ceriello A, Quagliaro L, Catone B, Pascon R, Piazzola M, Bais $\mathrm{B}$, et al. Role of hyperglycemia in nitrotyrosine postprandial generation. Diabetes Care. 2002;25(8):1439-43.

67. Hashiramoto M, Kaku K. Sirtuin 1 as a key player of 'metabolic memory'. J Diabetes Investig. 2013;4(1):34-6.

68. Winder WW, Hardie DG. AMP-activated protein kinase, a metabolic master switch: possible roles in type 2 diabetes. Am J Physiol. 1999;277(1 Pt 1):E1-10.

69. Ceriello A, Ihnat M, Ross K, Sismey A, Green DW, Kaltreider RC. Evidence for a cellular "memory" of hyperglycemic stress. Diabetes. 2005;54:218.

70. Park IH, Um JY, Hong SM, Cho JS, Lee SH, Lee SH, et al. Metformin reduces TGF-beta1-induced extracellular matrix production in nasal polyp-derived fibroblasts. Otolaryngol Head Neck Surg. 2014;150(1):148-53.

71. Jang AH, Kim YW. Metformin Reduces Inflammation and Lung Fibrosis in a Bleomycin-Induced Lung Injury Model (LB505). The FASEB Journal. 2014;28 Supl 1:505.

72. Matsumoto K, Sera Y, Abe Y, Tominaga T, Yeki Y, Miyake S.
Metformin attenuates progression of carotid arterial wall thickness in patients with type 2 diabetes. Diabetes Res Clin Pract. 2004;64(3):225-8.

73. Katakami N, Yamasaki Y, Hayaishi-Okano R, Ohtoshi K, Kaneto H, Matsuhisa M, et al. Metformin or gliclazide, rather than glibenclamide, attenuate progression of carotid intimamedia thickness in subjects with type 2 diabetes. Diabetologia. 2004;47(11):1906-13.

74. Li L, Mamputu JC, Wiernsperger N, Renier G. Signaling pathways involved in human vascular smooth muscle cell proliferation and matrix metalloproteinase-2 expression induced by leptin: inhibitory effect of metformin. Diabetes. 2005;54(7):2227-34.

75. Takahashi N, Shibata R, Ouchi N, Sugimoto M, Murohara T, Komori K. Metformin stimulates ischemia-induced revascularization through an eNOS dependent pathway in the ischemic hindlimb mice model. J Vasc Surg. 2015;61(2):489-96.

76. de Jager J, Kooy A, Schalkwijk C, van der Kolk J, Lehert P, Bets $\mathrm{D}$, et al. Long-term effects of metformin on endothelial function in type 2 diabetes: a randomized controlled trial. J Intern Med. 2014;275(1):59-70.

77. Pitocco D, Zaccardi F, Tarzia P, Milo M, Scavone G, Rizzo P, et al. Metformin improves endothelial function in type 1 diabetic subjects: a pilot, placebo-controlled randomized study. Diabetes Obes Metab. 2013;15(5):427-31.

78. Tousoulis D, Koniari K, Antoniades C, Miliou A, Noutsou M, Nikolopoulou A, et al. Impact of 6 weeks of treatment with low-dose metformin and atorvastatin on glucose-induced changes of endothelial function in adults with newly diagnosed type 2 diabetes mellitus: A single-blind study. Clin Ther. 2010;32(10):1720-8.

79. Zhang TX, Xu JX, Peng F, Chai DJ, Lin JX. Metformin reduces vascular endothelial dysfunction caused by an acute glucose load in patients with hypertension. Blood Press. 2013;22(2):106-13.

80. El Messaoudi S, Schreuder TH, Kengen RD, Rongen GA, van den Broek $\mathrm{PH}$, Thijssen $\mathrm{DH}$, et al. Impact of metformin on endothelial ischemia-reperfusion injury in humans in vivo: a prospective randomized open, blinded-endpoint study. PLOS ONE. 2014;9(4):e96062.

81. Cantoria MJ, Boros LG, Meuillet EJ. Contextual inhibition of fatty acid synthesis by metformin involves glucose-derived acetylCoA and cholesterol in pancreatic tumor cells. Metabolomics. 2014:10(1):91-104.

82. Geerling JJ, Boon MR, van der Zon GC, van den Berg SA, van den Hoek AM, Lombes M, et al. Metformin lowers plasma triglycerides by promoting VLDL-triglyceride clearance by brown adipose tissue in mice. Diabetes. 2014;63(3):880-91

83. Barnea M, Cohen-Yogev T, Chapnik N, Madar Z, Froy O. Effect of metformin and lipid emulsion on the circadian gene expression in muscle cells. Int J Biochem Cell Biol. 2014;53(1):151-61.

84. Yvan-Charvet L, Wang N, Tall AR. Role of HDL, ABCA1, and ABCG1 transporters in cholesterol efflux and immune responses. Arterioscler Thromb Vasc Biol. 2010;30(2):139-43.

85. Li D, Zhang Y, Ma J, Ling W, Xia M. Adenosine monophosphate activated protein kinase regulates ABCG1-mediated oxysterol efflux from endothelial cells and protects against hypercholesterolemia-induced endothelial dysfunction. Arterioscler Thromb Vasc Biol. 2010;30(7):1354-62.

86. Pentikainen PJ, Voutilainen E, Aro A, Uusitupa M, Penttila I, Vapaatalo H. Cholesterol lowering effect of metformin in combined hyperlipidemia: placebo controlled double blind trial. Ann Med. 1990;22(5):307-12.

87. Diehl LA, Fabris BA, Barbosa DS, De Faria EC, Wiechmann SL, Carrilho AJ. Metformin increases HDL3-cholesterol and decreases subcutaneous truncal fat in nondiabetic patients with HIV-associated lipodystrophy. AIDS Patient Care STDS. 2008;22(10):779-86.

88. Cittadini A, Napoli R, Monti MG, Rea D, Longobardi S, Netti PA, et al. Metformin prevents the development of chronic heart failure in the SHHF rat model. Diabetes. 2012;61(4):944-53.

89. Evans JM, Ogston SA, Emslie-Smith A, Morris AD. Risk of mortality and adverse cardiovascular outcomes in type 2 diabetes: a comparison of patients treated with sulfonylureas and metformin. Diabetologia. 2006;49(5):930-6.

90. Nichols GA, Gullion CM, Koro CE, Ephross SA, Brown JB. The incidence of congestive heart failure in type 2 diabetes: an update. Diabetes Care. 2004;27(8):1879-84. 
91. Nichols GA, Koro CE, Gullion CM, Ephross SA, Brown JB. The incidence of congestive heart failure associated with antidiabetic therapies. Diabetes Metab Res Rev. 2005 Feb;21(1):51-7.

92. Rosiak M, Postula M, Kaplon-Cieslicka A, Trzepla E, Czlonkowski A, Filipiak KJ, et al. Metformin treatment may be associated with decreased levels of NT-proBNP in patients with type 2 diabetes. Adv Med Sci. 2013 Dec;58(2):362-8.

93. Yin M, van der Horst IC, van Melle JP, Qian C, van Gilst WH, Sillje $\mathrm{HH}$, et al. Metformin improves cardiac function in a nondiabetic rat model of post-MI heart failure. Am J Physio Heart Circ Physiol. 2011 Aug;301(2):H459-68.

94. Whittington HJ, Hall AR, McLaughlin CP, Hausenloy DJ, Yellon DM, Mocanu MM. Chronic metformin associated cardioprotection against infarction: not just a glucose lowering phenomenon. Cardiovasc Drugs Ther. 2013 Feb;27(1):5-16.

95. Calvert JW, Gundewar S, Jha S, Greer JJ, Bestermann WH, Tian R, et al. Acute metformin therapy confers cardioprotection agains myocardial infarction via AMPK-eNOS-mediated signaling Diabetes. 2008 Mar;57(3):696-705.

96. Elmadhun NY, Sabe AA, Lassaletta AD, Chu LM, Sellke FW. Metformin mitigates apoptosis in ischemic myocardium. J Surg Res. 2014 Nov;192(1):50-8.

97. Lexis CP, van der Horst IC, Lipsic E, Wieringa WG, de Boer RA, van den Heuvel AF, et al. Effect of metformin on left ventricula function after acute myocardial infarction in patients withou diabetes: the GIPS-III randomized clinical trial. JAMA. 2014 Apr;311(15):1526-35.

98. Li J, Xu JP, Zhao XZ, Sun XJ, Xu ZW, Song SJ. Protective effect of metformin on myocardial injury in metabolic syndrome patients following percutaneous coronary intervention. Cardiology. 2014 Jan;127(2):133-9.

99. Calvert JW. Treating percutaneous coronary interventionrelated myocardial injury with metformin. Cardiology. 2014 Jan;127(2):130-2.

100. Giovannucci E, Harlan DM, Archer MC, Bergenstal RM, Gapstur SM, Habel LA, et al. Diabetes and cancer: a consensus report. Diabetes Care. 2010 Jul;33(7):1674-85.

101. Barone BB, Yeh HC, Snyder CF, Peairs KS, Stein KB, Derr RL, et al. Long-term all-cause mortality in cancer patients with preexisting diabetes mellitus: a systematic review and meta-analysis. JAMA. 2008 Dec;300(23):2754-64

102. Kaaks R, Johnson T, Tikk K, Sookthai D, Tjonneland A, Roswall $\mathrm{N}$, et al. Insulin-like growth factor I and risk of breast cancer by age and hormone receptor status-A prospective study within the EPIC cohort. Int J Cancer. 2014 Jun;134(11):2683-90.

103. Krett NL, Heaton JH, Gelehrter TD. Mediation of insulinlike growth factor actions by the insulin receptor in $\mathrm{H}-35$ rat hepatoma cells. Endocrinology. 1987 Jan;120(1):401-8.

104. Warburg O. On the origin of cancer cells. Science. 1956 Feb;123(3191):309-14.

105. Jalving M, Gietema JA, Lefrandt JD, de Jong S, Reyners AK, Gans RO, et al. Metformin: taking away the candy for cancer? Eur J Cancer. 2010 Sep;46(13):2369-80.

106. Gallagher EJ, LeRoith D. Diabetes, cancer, and metformin: connections of metabolism and cell proliferation. Ann N Y Acad Sci. 2011 Dec;1243:54-68.

107. Bowker SL, Yasui Y, Veugelers P, Johnson JA. Glucoselowering agents and cancer mortality rates in type 2 diabetes: assessing effects of time-varying exposure. Diabetologia. 2010 Aug;53(8):1631-7.

108. Colhoun HM, Group SE. Use of insulin glargine and cancer incidence in Scotland: a study from the Scottish Diabetes Research Network Epidemiology Group. Diabetologia. 2009 Sep;52(9):1755-65.

109. Currie CJ, Poole CD, Gale EA. The influence of glucose-lowering therapies on cancer risk in type 2 diabetes. Diabetologia. 2009 Sep;52(9):1766-77.

110. Libby G, Donnelly LA, Donnan PT, Alessi DR, Morris AD, Evans JM. New users of metformin are at low risk of incident cancer: a cohort study among people with type 2 diabetes. Diabetes Care. 2009 Sep;32(9):1620-5

111. Evans JM, Donnelly LA, Emslie-Smith AM, Alessi DR, Morris AD. Metformin and reduced risk of cancer in diabetic patients. BMJ. 2005;330(7503):1304-5.

112. Franciosi M, Lucisano G, Lapice E, Strippoli GF, Pellegrini F, Nicolucci A. Metformin therapy and risk of cancer in patients with type 2 diabetes: systematic review. PLoS One 2013;8(8):e71583.

113. Ben Sahra I, Le Marchand-Brustel Y, Tanti JF, Bost F. Metformin in cancer therapy: a new perspective for an old antidiabetic drug?. Mol Cancer Ther. 2010;9(5):1092-9.

114. Del Barco S, Vazquez-Martin A, Cufi S, Oliveras-Ferraros C, Bosch-Barrera J, Joven J, et al. Metformin: multi-faceted protection against cancer. Oncotarget. 2011;2(12):896-917.

115. Shaw RJ. LKB1 and AMP-activated protein kinase control of mTOR signalling and growth. Acta Physiol (Oxf). 2009;196(1):65-80.

116. Huang X, Wullschleger S, Shpiro N, McGuire VA, Sakamoto K, Woods YL, et al. Important role of the LKB1-AMPK pathway in suppressing tumorigenesis in PTEN-deficient mice. Biochem J. 2008;412(2):211-21.

117. Dowling RJ, Zakikhani M, Fantus IG, Pollak M, Sonenberg N. Metformin inhibits mammalian target of rapamycin-dependent translation initiation in breast cancer cells. Cancer Res. 2007;67(22):10804-12.

118. Esfahanian N, Shakiba Y, Nikbin B, Soraya H, Maleki-Dizaji N, Ghazi-Khansari M, et al. Effect of metformin on the proliferation, migration, and MMP-2 and -9 expression of human umbilical vein endothelial cells. Mol Med Rep. 2012;5(4):1068-74.

119. Rattan R, Ali Fehmi R, Munkarah A. Metformin: an emerging new therapeutic option for targeting cancer stem cells and metastasis. J Oncol. 2012;2012:928127.

120. Xavier DO, Amaral LS, Gomes MA, Rocha MA, Campos PR, Cota $\mathrm{BD}$, et al. Metformin inhibits inflammatory angiogenesis in a murine sponge model. Biomed Pharmacother. 2010;64(3):220-5.

121. Ersoy C, Kiyici S, Budak F, Oral B, Guclu M, Duran C, et al. The effect of metformin treatment on VEGF and PAI-1 levels in obese type 2 diabetic patients. Diabetes Res Clin Pract. 2008;81(1):56-60.

122. Barriere G, Tartary M, Rigaud M. Metformin: a rising star to fight the epithelial mesenchymal transition in oncology. Anticancer Agents Med Chem. 2013;13(2):333-40.

123. Cufi S, Vazquez-Martin A, Oliveras-Ferraros C, Martin-Castillo B, Joven J, Menendez JA. Metformin against TGFbeta-induced epithelial-to-mesenchymal transition (EMT): from cancer stem cells to aging-associated fibrosis. Cell cycle. 2010;9(22):4461-8.

124. Ben Sahra I, Laurent K, Loubat A, Giorgetti-Peraldi S, Colosetti $\mathrm{P}$, Auberger $\mathrm{P}$, et al. The antidiabetic drug metformin exerts an antitumoral effect in vitro and in vivo through a decrease of cyclin D1 level. Oncogene. 2008;27(25):3576-86.

125. Ben Sahra I, Regazzetti C, Robert G, Laurent K, Le MarchandBrustel Y, Auberger P, et al. Metformin, independent of AMPK, induces mTOR inhibition and cell-cycle arrest through REDD1. Cancer Res. 2011;71(13):4366-72

126. Zhuang Y, Miskimins WK. Cell cycle arrest in Metformin treated breast cancer cells involves activation of AMPK, downregulation of cyclin D1, and requires p27Kip1 or p21Cip1. J Mol Signal. 2008;3:18.

127. Isakovic A, Harhaji L, Stevanovic D, Markovic Z, SumaracDumanovic M, Starcevic V, et al. Dual antiglioma action of metformin: cell cycle arrest and mitochondria-dependent apoptosis. Cell Mol Life Sci. 2007;64(10):1290-302.

128. Liu B, Fan Z, Edgerton SM, Deng XS, Alimova IN, Lind SE, et al. Metformin induces unique biological and molecular responses in triple negative breast cancer cells. Cell cycle. 2009;8(13):2031-40.

129. Eikawa S, Nishida M, Mizukami S, Yamazaki C, Nakayama E, Udono H. Immune-mediated antitumor effect by type 2 diabetes drug, metformin. Proc Natl Acad Sci U.S.A. 2015;112(6):1809-14.

130. Goodwin PJ, Stambolic V. Obesity and insulin resistance in breast cancer--chemoprevention strategies with a focus on metformin. Breast. 2011;20(Suppl 3):S31-5.

131. Qu C, Zhang W, Zheng G, Zhang Z, Yin J, He Z. Metformin reverses multidrug resistance and epithelial-mesenchymal transition (EMT) via activating AMP-activated protein kinase (AMPK) in human breast cancer cells. Mol Cell Biochem. 2014;386(1-2):63-71.

132. Iliopoulos D, Hirsch HA, Struhl K. Metformin decreases the dose of chemotherapy for prolonging tumor remission in mouse xenografts involving multiple cancer cell types. Cancer Res. 2011;71(9):3196-201.

133. Kim J, Lim W, Kim EK, Kim MK, Paik NS, Jeong SS, et al. Phase II randomized trial of neoadjuvant metformin plus letrozole versus placebo plus letrozole for estrogen receptor positive postmenopausal breast cancer (METEOR). BMC Cancer. 
2014;14:170

134. Rocha GZ, Dias MM, Ropelle ER, Osorio-Costa F, Rossato FA, Vercesi AE, et al. Metformin amplifies chemotherapy-induced AMPK activation and antitumoral growth. Clin Cancer Res. 2011;17(12):3993-4005.

135. Hwang IC, Park SM, Shin D, Ahn HY, Rieken M, Shariat SF. Metformin Association with Lower Prostate Cancer Recurrence in Type 2 Diabetes: a Systematic Review and Meta-analysis. Asian Pac J Cancer Prev. 2015;16(2):595-600.

136. Raval AD, Thakker D, Vyas A, Salkini M, Madhavan S, Sambamoorthi U. Impact of metformin on clinical outcomes among men with prostate cancer: a systematic review and metaanalysis. Prostate Cancer Prostatic Dis. 2015;18:110-21.

137. Yu H, Yin L, Jiang X, Sun X, Wu J, Tian H, et al. Effect of metformin on cancer risk and treatment outcome of prostate cancer: a meta-analysis of epidemiological observational studies. PLoS One. 2014;9(12):e116327.

138. Col NF, Ochs L, Springmann V, Aragaki AK, Chlebowski RT. Metformin and breast cancer risk: a meta-analysis and critical literature review. Breast Cancer Res Treat. 2012;135(3):639-46.

139. Rego DF, Pavan LM, Elias ST, De Luca Canto G, Guerra EN.
Effects of metformin on head and neck cancer: A systematic review. Oral Oncol. 2015;51(5):416-22.

140. Sakoda LC, Ferrara A, Achacoso NS, Peng T, Ehrlich SF, Quesenberry CP, Jr., et al. Metformin use and lung cancer risk in patients with diabetes. Cancer Prev Res (Phila). 2015;8(2):174-9.

141. Zhang ZJ, Bi Y, Li S, Zhang Q, Zhao G, Guo Y, et al. Reduced risk of lung cancer with metformin therapy in diabetic patients: a systematic review and meta-analysis. Am J Epidemiol. 2014;180(1):11-4.

142. Wang Z, Lai ST, Xie L, Zhao JD, Ma NY, Zhu J, et al. Metformin is associated with reduced risk of pancreatic cancer in patients with type 2 diabetes mellitus: a systematic review and metaanalysis. Diabetes Res Clin Pract. 2014;106(1):19-26.

143. Pinilla AE. Construcción y evaluación de un perfil de competencias profesionales en medicina interna. Colección Desarrollo Humano. Bogotá: Editorial Universidad Nacional de Colombia; 2015.

144. Patiño JF. Humanismo, medicina y ciencia. En: Silva G (Ed.). Colección Obra Selecta. Bogotá: Editorial Universidad Nacional de Colombia; 2011. 